\title{
Pseudohyperkalemia in a patient with chronic myeloid leukaemia
}

\author{
Jacobsz $\boldsymbol{M}$, MBChB \\ Department of Chemical Pathology, University of Pretoria \\ Frantzen L, MBChB, MMed Chemical Pathology FC Path(Chem)(SA), BSc (Medsci) \\ Correspondence: Dr M Jacobsz, e-mail: madelenedj@mweb.co.za
}

\section{Abstract}

Hyperkaliaemia is a common finding in the hospital and outpatient setting. Often the cause can be identified easily. If the cause seems obscure, further investigation is warranted.

SA Fam Pract 2007;49(7): 50

\section{Case history}

A 20-year-old female patient presented to the emergency department of a secondary hospital, and was subsequently referred to a tertiary hospital, with advanced chronic myeloid leukaemia with a leukocyte count of $349.4 \times 10^{9} / \mathrm{L}$, a blast cell percentage of $70 \%$ and hyperkaliaemia. The raised potassium value could not be attributed to the usual causes of hyperkaliaemia, e.g. kidney dysfunction, acid-base changes, mineralocorticoid deficiency and diabetic ketoacidosis.

Repeat sampling and repeat analysis confirmed the potassium value. No haemolysis was apparent and the specimen was processed within one hour. The quality control assessment of the analyser was within limits. The reported values were as follows:

Morning of day 1 : serum $\mathrm{K}=12.4 \mathrm{mmol} / \mathrm{L}$ Afternoon of day 1 : serum $\mathrm{K}=9.6 \mathrm{mmol} / \mathrm{L}$

No clinical manifestations (gastrointestinal symptoms) or electrocardiogram (ECG) changes associated with hyperkaliaemia were present. The patient passed away before a plasma sample could be obtained to evaluate the in vivo potassium value.

\section{Discussion}

Pseudohyperkalemia is defined as an elevated serum potassium value (in vitro) in a patient with an in vivo potassium level within the reference limits. ${ }^{1} \mathrm{~A}$ high index of suspicion is warranted when an elevated potassium value is found without any clinical manifestations, ECG changes or an obvious cause.
The clinical picture depends on the level and the rate of potassium increase. Severe symptoms and signs (cardiovascular, neuromuscular and intestinal) may not occur until the potassium level reaches $7 \mathrm{mmol} / \mathrm{L}$. The earliest ECG changes ("peaked T-waves") occur after the potassium value reaches a level of $6.5 \mathrm{mmol} / \mathrm{L}$. As the levels increase, $\mathrm{P}$ wave flattening, prolonged PR intervals and QRS broadening appear. When levels reach 8 to $10 \mathrm{mmol} / \mathrm{L}$, asystole or fibrillation may occur. ${ }^{2}$

Pseudohyperkalemia can be attributed to sampling conditions and technique, and transport and processing prior to analysis. The underlying mechanisms include contamination, cell damage and metabolic changes.

Cell damage can be caused by vigorous aspiration, the use of vacuum tubes, vigorous shaking ${ }^{1}$ and platelet rupture during coagulation (if the platelet count is more than $\left.500 \times 10^{9} / \mathrm{L}\right){ }^{3}$ Slight (50 mg haemoglobin/dl), moderate (200 mg haemoglobin/dl) and gross (> $500 \mathrm{mg}$ haemoglobin/dl) haemolysis may increase the potassium values by approximately $3 \%, 12 \%$ and $30 \%$ respectively. ${ }^{4}$ In patients with leukaemia, the leucocytes have abnormal fragility and this may lead to potassium release when exposed to mechanical stress. A significant potassium elevation occurs when the leukocyte count exceeds 50 to $100 \times 10^{9} / \mathrm{L}$, which may occur in haematological malignancies and severe infections. $^{5}$

Muscle clenching and failure to release the tourniquet before sampling may lead to anaerobic glycolysis with limited adenosine triphosphate (ATP) production. A delay in centrifugation (prolonged serum-cell contact leading to glucose depletion) and temperature changes (chilling inhibits glycolysis) lead to inhibition of glycolysis with decreased availability of ATP. This leads to inhibition of the sodium-potassiumATPase pump that results in potassium leakage from cells. At $4{ }^{\circ} \mathrm{C}$, potassium may increase by up to $2 \mathrm{mmol} / \mathrm{L}$ after four hours and, at $25^{\circ} \mathrm{C}$ by up to 0.2 $\mathrm{mmol} / \mathrm{L}$ in 1.5 hours. $^{4}$

Pseudohyperkalemia in a serum sample can be confirmed by comparison with plasma potassium values. ${ }^{5}$ The most reliable estimation of the potassium value is to collect a sample with minimal clenching/tourniquet time in a lithium heparin tube, transport the sample at a temperature of between 25 and $37^{\circ} \mathrm{C}$, immediately separate the plasma from the cells, and follow this by analysis within one hour. ${ }^{4}$ If speedy transport, separation and analysis are not readily available, point-of-care testing is an alternative. ${ }^{5}$

\section{Conclusion}

All medical practitioners who evaluate blood results, whether in a polyclinic or an intensive care unit, must be aware of the possibility of pseudohyperkalemia in a patient in whom the clinical picture is not consistent with the serum potassium value. Failure to do so may lead to incorrect diagnosis and improper management.

\section{References}

Chornbery JM. Pseudohyperkalemia due oneumatic tube transport in a leukemic patient. Am J Kidney Dis 2005:46:746-8.

2 Schaefer TJ. Wolford RW Disorders of potassium. Emerg Med Clin N Am 2005:23:723-47.

3. Thurlow V, Ozevlat $H$, Jones SA, Bailey IR. Establishing a practical blood platelet threshold to avoid reporting spurious potassium results due to thrombocytosis. An

Clin Biochem 2005;42:196-9.
Burtis CA, Ashwood ER, Bruns DE. Tietz textbook of clinical chemistry and molecular diagnostics. 4th ed Philadelphia: Elsevier Inc.; 2006. p. 984-6.

emia in extreme leucocytosis. Am J Nephrol 1995;15:450-2. 